\title{
The effects on Thailand of China's import restrictions on waste: measures and challenges related to the international recycling of waste plastic and e-waste
}

\author{
So Sasaki ${ }^{1,2}$ \\ Received: 24 December 2019 / Accepted: 21 August 2020 / Published online: 22 September 2020 \\ (c) Springer Japan KK, part of Springer Nature 2020
}

\begin{abstract}
This paper has outlined the measures and challenges facing Thailand, which was forced to address a surge in imports of plastic waste and e-waste after China imposed restrictions on its own imports of waste material. Thailand had imposed import restrictions and created an import permit system prior to China's decision. However, the nation was not prepared for the extent of the subsequent smuggling and other illegal activities, as evidenced by the various problems related to the permit system and customs enforceability in 2018. In response, Thailand banned imports of plastic waste and e-waste, resulting in a loss of business opportunities for companies with legal import permits. Other nations in Southeast Asia, such as Vietnam, Malaysia, and the Philippines, witnessed a similar surge in imports of plastic waste and e-waste after China's decision to restrict waste imports. These nations subsequently also imposed import bans and/or restrictions. However, the enforceability of such bans and restrictions may be limited in Asia. Thus, exporting countries must secure an appropriate international recycling mechanism.
\end{abstract}

Keywords The Basel Convention · Circular economy · Trade statistics · Illegal imports · Customs

\section{Introduction}

China imposed restrictions on its imports of recyclable waste at the end of 2017, creating a global challenge for exporting countries as they re-examined their dependence on China for recycling. In July 2017, the Chinese government stated that it would ban imports of 24 types of solid waste (in four categories, including household plastic waste) by the end of that year. According to State Council of China (2017), in recent years, various regions and relevant departments have done a lot of work in combating smuggling of foreign waste and strengthening supervision of imported solid waste, and achieved certain results. However, due to the persistence of the idea of focusing on development and disregard environmental protection in some places, some enterprises

So Sasaki

so-s@tamacc.chuo-u.ac.jp

1 Faculty of Economics, Chuo University, 742-1 Higashinakano, Hachioji-shi, Tokyo 192-0393, Japan

2 Faculty of Economics, Chulalongkorn University, Phayathai Road, Pathumwan, Bangkok 10330, Thailand are taking risks to obtain illegal benefits, and the illegal entry of foreign garbage has been banned repeatedly, seriously endangering the health of the people and the safety of China's ecological environment [1]. China, known as the "world's factory", had until then served as a major recycling center for waste and scrap. Thus, the nation's policy change had a tremendous effect on various countries around the world, an impact still being felt today [2].

This paper focuses on the trade issues of plastic waste and "e-waste" (discarded electronic appliances). Some case studies of plastic waste pointed out that as re-processing of waste is one of the major sources of pollution in the recycling processes, a mechanism is needed to control and reduce the emission impact in the re-processing as a key to facilitate the globalized reverse supply chain and avoid spreading pollutants overseas [3], and the geography of the plastic waste trade is structured by Asia as the dominant importer and North America and Europe as the largest sources of plastic waste [4]. Now for e-waste, according to statistics developed by the United Nations University, in 2021, the total volume of e-waste generated worldwide will surpass 52 million tons and by 2050 , in the worst-case scenario, it could reach 120 million tons. Current estimates show that, in 2018, only $20 \%$ 
of the e-waste generated globally was collected properly, the rest was discarded or managed informally [5]. Under such circumstances, China has been working on recycling e-waste early among emerging countries since 2011. China has built a territory-based formal e-waste recycling system as a response to the global e-waste challenge. This system created a division of labor between the informal sector and formal recycling plants by providing a subsidy to the latter to buy waste products collected by the former [6]. As a result of this effort, the emission reduction benefits of solid waste are estimated to be 5.37 billion yuan (770 million US\$) from 2013 to 2017 in 29 provinces in China e-waste [7].

Furthermore, developing countries currently without stringent environmental regulations will likely become the new "pollution haven" of solid waste from developed countries and even emerging economies such as China itself. To truly reap the benefits from China's new policies which are originally designed for environmental sustainability and social justice, the global community needs to develop appropriate policy framework to prevent the unintended consequences [8]. In particular, following China's decision, emerging nations in Asia, such as Thailand, Vietnam, and Malaysia, lost an export destination for their plastic waste, while simultaneously facing an increase in imports of e-waste from major industrialized nations, such as Japan and those in the West. As a result, the governments of these emerging nations were forced to address this issue by the middle of 2018. However, little has been reported on the details of change in Southeast Asian after China's decision.

This paper discusses the measures and challenges related to the international recycling of plastic waste and e-waste from the perspective of Thailand with analysis of trade and related governmental statistics. Thailand's own restrictions on imports of plastic waste and e-waste were imposed before the sudden increase in demand from major industrialized countries following China's decision, and thus failed to function correctly. This background is useful as a means of examining the enforceability of similar import restrictions increasingly being implemented in various countries in Asia. The impact of various import regulations and problems with the current situation are discussed based on (1) 30 interviews at recycling plants and with officials from relevant ministries and agencies, (2) information gathered from various relevant reports (around 300, including television and newspaper reports and press releases by the Thai government), and (3) analysis of changes in trade flows using relevant customs and government statistics.

The next section outlines the changes in the volume of trade before and after China imposed its restrictions on imports of recyclable waste, and discusses several measures and challenges related to plastic waste and e-waste in Thailand. Lastly, the challenges around building an appropriate international recycling mechanism in Asia are discussed.

\section{Measures and challenges related to the international recycling of plastic waste}

\section{Changes in trade in plastic waste after China imposed import restrictions on recyclable waste}

Thailand issued "Ministerial Notification: permission criteria of import plastic waste in 1996" to restrict imports of plastic waste before China imposed its restrictions on imports of recyclable waste. Specifically, Thailand allowed imports by factories that had obtained approval from the Department of Industrial Works (DIW) of the Ministry of Industry (MOI), which regulates industrial waste. These factories were subject to a myriad of regulations. For example, they were required to submit annual recycling plans, and all imported plastic waste had to first be cleansed and cut into pieces no longer than $2 \mathrm{~cm}$ on any side.

However, the volume of trade in plastic waste in Thailand indicates an increase in imports in the latter half of 2017, in anticipation of the effects of China's import restrictions that were to be implemented at the end of that year. Imports exceeded exports for the first time in 2018, when Thailand imported 553,000 tons of plastic waste, 3.6 times more than the year before. Thailand exported more than $80 \%$ of its plastic waste to China in 2013, but this figure fell to $14.2 \%$ in 2018 (see Fig. 1). In other words, Thailand lost an export destination for its own plastic waste, even as it faced an increase in imports from major industrialized nations. This situation required urgent attention.

Of the 553,000 tons of plastic waste imported in 2018, 188,000 tons came from Japan, making it Thailand's largest trading partner. Furthermore, the unit import price from Japan was THB 10.44 per kilogram (USD 0.35), compared with the average unit import price of THB 6.71 per kilogram (USD 0.22) from other countries. This implies that the plastic waste from Japan was of relatively high quality.

\section{Import measures and challenges related to plastic waste}

In May 2018, Thai police raided several recycling companies, which revealed the extent of the problem of illegal imports (e.g., through smuggling and the false labeling of e-waste as plastic waste). In response, in July of that year, the Thai government suspended imports of plastic waste and e-waste, and the government's future direction was approved in August. With regard to plastic waste, it was announced that an import quota would be established 
Fig. 1 Volume of trade in plastic waste in Thailand (left axis) and the ratio of exports to China (right axis)

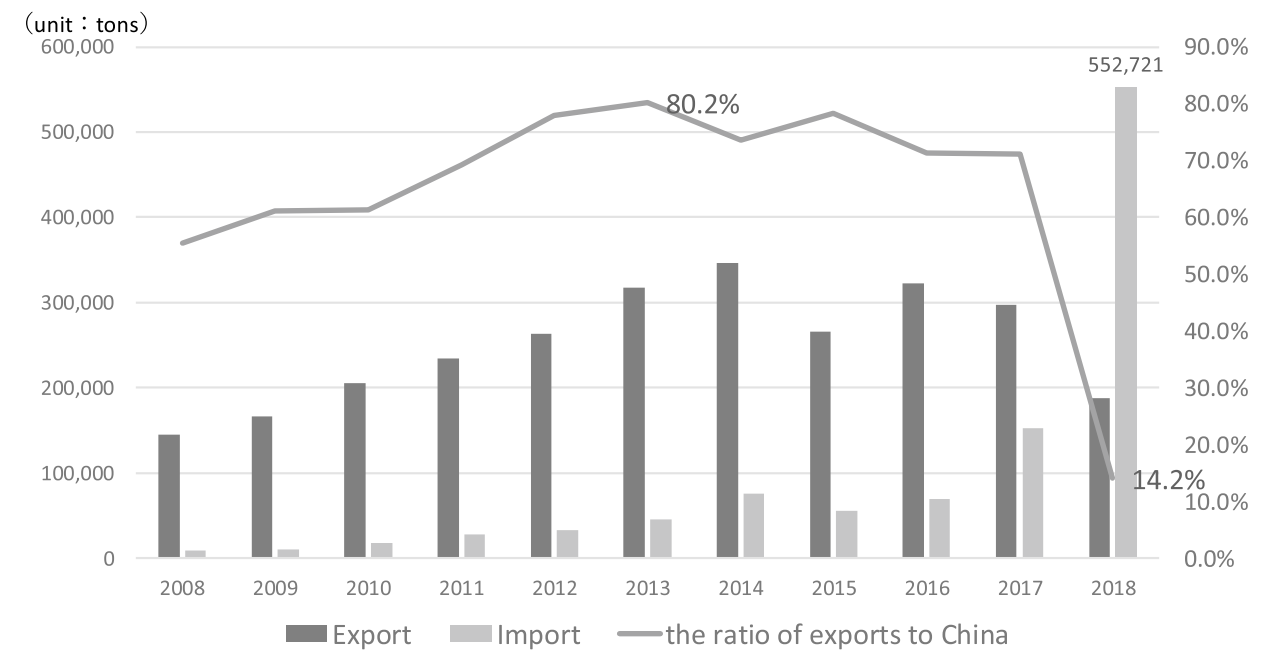

(Source) Created by the author using Thai customs trade statistics (HS Code: 3915 ) during a 2-year grace period, after which imports would be banned completely by the end of 2020 . However, no import quotas were established. Thus, when the import permits ended at the end of June 2018, this effectively ended imports of plastic waste [9].

However, the issues related to imports of plastic waste center around the enforceability of regulations against smuggling and illegal processing. Those engaging in such activities do not obey laws to begin with. For this reason, the effectiveness of the import ban may be limited.

In July 2018, the Thai government halted the issuance of new import permits for plastic waste. Because existing import permits were valid for 1 year only, no valid permits existed after July 2019, and thus imports of plastic waste should have stopped. Nevertheless, imports of plastic waste continued (e.g., by falsely declaring plastic waste as plastic products at customs).

This change in regulation had far-reaching consequences. For example, a Japanese company in Thailand that had a permit to import plastic waste from Japan to produce carpets for sale in Japan had to switch to plastic waste produced in Thailand. As a result, the company's earnings deteriorated because it had to pay the equivalent cost of buying unused materials. As another example, a recycling company that had been licensed to import plastic waste to produce recycled materials was forced to halt imports and change its core business.

Thus, the import ban in Thailand resulted in a loss of business opportunities for recycling companies with official import permits for plastic waste.

\section{Measures and challenges related to the international recycling of e-waste}

\section{Changes in e-waste trade after China restricted imports of recyclable waste}

In 2002, China strengthened its regulations on imports of secondhand home appliances. As a result, in September 2003, the DIW in Thailand imposed restrictions on imports of secondhand home appliances by the Notification of the Department of Industrial Works titled "Re: Importing conditions for used electrical and electronic equipment that is a hazardous substance into the Kingdom of Thailand." in response to a concern that a flood of discarded appliances would enter the nation from major industrialized countries after China's decision. The restrictions, as in the case of similar regulations in China, cover 29 items, including personal computers, television sets, and components. Secondhand electronic devices older than 3 years from the date of production ( 5 years for copy machines) are banned entirely if the purpose is for sale or reuse. However, imports were still permitted for disassembling and recycling, under certain conditions. For example, such products must still have some economic value, be handled by a factory registered with the DIW, and imported from signatory countries of the Basel Convention. Thus, Thailand's restrictions on imports of secondhand home appliances reflect the nation's concern for 
the secondary market, and for the growth of the recycling industry. In this respect, these restrictions are different in character from those in China, which places, in principle, a blanket ban on all secondhand appliances.

The Hazardous Substances List is updated based on the Notification of the Ministry of Industry regarding lists of hazardous substances B.E. 2538 (1995) and assigned hazardous substance codes. "E-waste/e-scraps" approved for import according to the same Notification is assigned the hazardous substance code 3241, "used EEE" is assigned 3322, and "used EEE for reusing parts" is assigned 3323. Trade statistics are released based on the approval results. With regard to the actual volumes of exports and imports permitted under the import restrictions on secondhand home appliances, import permits for e-waste and e-scrap remained capped at 2000 tons until 2015. However, the volume began to increase in 2016, and surged to 53,291 tons in 2017, 5.7 times the volume of the year before. Similarly, 30,745 tons of used electronic and electronic equipment (EEE) were imported in 2017, with the volume showing a consecutive annual increase (see Table 1). However, the import volume of e-waste decreased in 2018 from that of the previous year after a smuggling case was identified in mid-2018 that resulted in stronger enforcement measures being implemented.

The import volumes of e-waste and e-scrap surged, as did that of plastic waste, after China imposed its restrictions on imports of recyclable waste. In Thailand, as in other Southeast Asian countries, the incidence of smuggling and illegal processing of e-waste from Hong Kong and China became a major concern.

In May 2018, police searched Wai Mei Dat (WMD) Thai Recycling, based in the province of Chachoengsao, after area residents filed a complaint with a DIW regional office about the smell from the company's factory. It was found that the company was hiring undocumented workers from Laos and Myanmar for THB 9,000 a month, which is below the legal minimum wage, to disassemble e-waste. The company used acid to collect precious metals from the waste and discarded the liquid produced in the process [10].
Table 1 Export-import permits issued under restrictions on imports of secondhand home appliances (tons)

\begin{tabular}{llllllll}
\hline $\begin{array}{l}\text { Hazardous substance } \\
\text { (hazardous substance } \\
\text { code) }\end{array}$ & 2012 & 2013 & 2014 & 2015 & 2016 & 2017 & 2018 \\
\hline $\begin{array}{l}\text { e-waste/e-scraps (3241) } \\
\text { Export }\end{array}$ & 1214 & 1016 & 1855 & 3820 & 7840 & 7582 & 7137 \\
Import & 1739 & 1692 & 1856 & 1778 & 9312 & 53,291 & 38,423 \\
Net & -525 & -676 & -1 & 2042 & -1472 & $-45,708$ & $-31,286$ \\
Used EEE (3322) & 0 & 0 & 0 & 0 & 0 & 0 & 0 \\
Export & 6455 & 3023 & 6813 & 11,716 & 21,784 & 30,745 & 7567 \\
Import & -6455 & -3023 & -6813 & $-11,716$ & $-21,784$ & $-30,745$ & \\
Net & 2595 & 1482 & 2742 & 4161 & 2361 & 1508 & 887 \\
Used EEE for reusing parts $(3323)$ & & & & & & \\
Export & -2595 & -1482 & -2742 & -4161 & -2361 & -1508 & -887 \\
Import & & & & & & & \\
\hline
\end{tabular}

(Source) Department of industrial works, list of hazardous substances listed as hazardoussubstances imported-export and consider licensing (conditions passed) (in Thai)

Table 2 Results of inspection of licensed importers of e-waste in Thailand

\begin{tabular}{llll}
\hline Company name & Investor's countries & $\begin{array}{l}\text { Permission application volume in Judgment by DIW } \\
2018 \text { (tons) }\end{array}$ & Illegal (smuggling) \\
\hline Yong Tang Thai Co., Ltd & China & 30,000 & Illegal (smuggling) \\
JPS Metal Group International CO., Ltd & China & 60,000 & Illegal (smuggling) \\
Viro Green (Thailand) Co., Ltd & China & 13,000 & Corrective Recom- \\
Mhing Enginnering (Thailand) Co., Ltd & Malaysia & 150 & mendation (License \\
& & & Expiration) \\
OGI Co., Ltd & Korea & 15,000 & Illegal (smuggling) \\
SS Import Export International Co., Ltd & China & 2000 & Illegal (smuggling) \\
Fuji Xerox Eco Manufacturing Co., Ltd & Japan & 1440 & Legal \\
\hline
\end{tabular}

(Source) News reports and interviews with DIW 
In response to this incident, regulators checked containers unloaded from ships and found many illegal imports of e-waste and plastic waste. Subsequently, the DIW inspected seven companies that had been granted import permits. Of these, Fuji Xerox Eco Manufacturing Co., Ltd., a Japaneseaffiliated company, was the only importer found to be conforming to the law (see Table 2).

Tables 1 and 2 show that some holders of import permits for e-waste submitted more permission applications than the combined number of permits issued under the 2017 import restrictions on household appliances, implying that the regulations on imports of secondhand home appliances have lost their effectiveness.

\section{Import measures and challenges related to e-waste}

After the inspection of licensed e-waste importers and the subsequent customs enforcement actions, on June 22, 2018, the MOI announced the following measures: (1) the suspension of imports of e-waste and discarded secondhand components; (2) the suspension of imports of discarded products (such as synthetic metal scrap, wires, motors, transformers, generators, and batteries); and (3) restrictions on imports of discarded secondhand devices that have been repaired, modified, or changed, either for export purposes or for domestic sale. As a result, no imports have been allowed for these items since July of that year [9].

These changes were particularly severe on Fuji Xerox Eco Manufacturing Co., Ltd., which was found to be complying with Thailand's legal requirements during the inspection into licensed e-waste importers. The company had achieved a recycling ratio of at least $99 \%$, with the remaining $1 \%$ processed properly in Japan under the Basel Convention. The company had consistently been recognized as a superior business operator by the DIW. In addition, in recent years, the company had been focusing on the reuse of toner cartridges and the reconditioning of copy machines, achieving a reuse ratio of $22 \%$ in terms of weight, and creating a business model for other manufacturers to emulate in the international "Circular Economy". However, the company could no longer maintain its business model after the MOI suspended imports of e-waste and used components, and was finally liquidated in June 2019.

Nevertheless, even if imports of e-waste and other secondhand items are banned entirely, the effects on those engaging in smuggling or other illegal import practices would be limited, because they do not bother obtaining e-waste import permits to do so. Furthermore, the blanket import ban resulted in a loss of business opportunities for recycling companies with legal import permits for e-waste, creating a market in which "bad money drives out good," as in the case of the plastic waste market.

\section{Political implications/suggestions}

As above, Thailand had imposed import restrictions and created an import permit system prior to China's decision. However, the nation was not prepared for the extent of the subsequent smuggling and other illegal activities, as evidenced by the various problems related to the permit system and customs enforceability in 2018. In response, Thailand banned imports of plastic waste and e-waste, resulting in a loss of business opportunities for companies with legal import permits.

It is reported that, at the committee meeting at which the decision to ban imports of waste plastic and e-waste was taken, the (then) Minister of Natural Resources and Environment, Surasak Karnjanarat, remarked that Thailand should recycle waste produced in the country. This seems reasonable, but it takes time to achieve this, so the related domestic policies must be considered in short, medium, and long-term.

In the short term, Thai's Cabinet not only banned imports of waste plastic and e-waste, but also approved the roadmap for the management of waste plastic in April 2019, and set some items to be banned by the end of 2019 such as cap seals (which indicate that PET bottles have not been opened), oxodegradable plastics (plastics with an additive that causes them to fragment when subjected to light or heat), and microplastics (used in cosmetics as well as face and body wash). In addition, the use of plastic shopping bags with a thickness of $36 \mu \mathrm{m}$ or less, foam food containers, disposable plastic cups, and plastic straws will be banned by 2022 [11]. Among these items, convenience stores and shopping malls have been banned from freely distributing plastic bags from the beginning of 2020; however, container and plastic packaging waste has increased due to increased food delivery for COVID-19 measures.

In the medium term, sorting waste and industrial standards are needed to improve the quantity and quality issues of recycled materials. In practice, scrap iron and waste paper that are used as recycled materials are imported because not enough is generated in Thailand, while waste plastic, for which there is little demand as a recycled material in Thailand, is exported, leading to problems in quantity such as mismatch issues between supply and demand. Furthermore, because municipal solid waste in Thailand is not sorted, some materials cannot be recycled and have problems in quality. Therefore, it is also important to ensure that demand exists for recycled products. To ensure an adequate level of quality for recycled products, and to reduce the transaction cost between the suppliers and buyers of recycled products, industrial standards, which are less in Thailand, should be developed for recycled goods. Besides the international initiatives mentioned in 
this paper, domestic Thai recycling initiatives will also be important in the future.

In the long term, Thailand should consider recycling laws. The daily volume of waste per person in Thailand is $1130 \mathrm{~kg}$ - the same as that in Japan in 1995, when its first recycling law, the Containers and Packaging Recycling Law, was enacted. It also seems necessary for Thailand to properly collect different types of waste separately to facilitate recycling and to enact recycling law with clear allocation of the roles of individual citizens, government, and business. In particular, the fact that using plastic shopping bags to dispose of garbage has become difficult after the ban on their free distribution represents an opportunity to introduce chargeable garbage bags to encourage separate collection on different days and by type of waste. E-waste recycling bill was not enacted because its passage was interrupted by a general election in April 2019, and it is currently being re-examined. Thailand's e-waste recycling bill for 2017 changed the responsibility of the manufacturers from bearing the financial burden of collecting e-waste. However, collectors designated by manufacturers are forced to compete on the purchase price, which includes the environmental cost, with the informal sector, thus making collection practically difficult [12]. Therefore, the recycling fee and collection system (in the form of a pilot project entrusted to the Federation of Thai Industries by the PCD from 2020) is being re-examined, so this seems a reasonable countermeasure and would take a few more years.

International trade and that of other nations in Southeast Asia, such as Vietnam, Malaysia, and the Philippines, witnessed a similar surge in imports of plastic waste and e-waste after China's decision to restrict waste imports. These nations subsequently also imposed import bans and/or restrictions. However, as discussed here, the enforceability of such bans and restrictions may be limited in Asia. Thus, exporting countries must secure an appropriate international recycling mechanism. Against this background, it was significant that the 14th meeting of the Conference of the Parties to the Basel Convention, held in May 2019, decided to control "unclean plastic waste," and provisionally adopted e-waste guidelines $[13,14]$. The amended annexes to the Basel Convention, rather than banning exports of plastic waste, require that the exporter obtain prior informed consent from the receiving country before exporting unclean waste. After the latest Basel Convention annex revision, contaminated plastic waste will be specified by the beginning of 2021. Signatory countries have also expressed concern regarding what qualifies as, or does not qualify as, waste according the e-waste guidelines; a review by an expert working group has been extended. This requirement clarifies the responsibility on the part of the exporting nations with regard to the quality of plastic waste being exported. In addition, the standards for secondhand items and e-waste would be clarified further if e-waste guidelines were provided on the age and the remaining life of electronic equipment. The debate surrounding contaminated plastic waste is therefore likely to have an impact on the decision regarding what is, or is not, waste according to the e-waste guidelines.

If these initiatives at the Basel Convention enable exporting nations to set up a proper international recycling mechanism, the international mismatch between supply and demand for the recycling of plastic waste would be resolved. In addition, if an adequate recovery volume can be secured in this recycling process, this may stimulate private sector investment in e-waste recycling facilities in Southeast Asia.

\section{Conclusion}

This paper has outlined the measures and challenges facing Thailand, which was forced to address a surge in imports of plastic waste and e-waste after China imposed restrictions on its own imports of waste material. The major findings were indicated as follows:

1. Imports exceeded exports for the first time in 2018, when Thailand imported 553,000 tons of plastic waste, 3.6 times more than the year before.

2. Thai government halted the issuance of new import permits for plastic waste, and it resulted in a loss of business opportunities for recycling companies with official import permits for plastic waste.

3. The volume of e-waste/e-scraps surged to 53,291 tons in 2017, 5.7 times the volume of the year before. Similarly, 30,745 tons of used electronic and electronic equipment were imported in 2017.

4. The blanket import ban resulted in a loss of business opportunities for recycling companies with legal import permits for e-waste.

5. Thailand adapted the import ban of plastics and e-waste, and prohibition of some plastics in the short term, the quality and quantity of recycled materials need to be improved in the medium term, and the recycling law must be considered in the long term.

6. The debate surrounding contaminated plastic waste in the Basel Convention is therefore likely to have an impact on the decision regarding what is, or is not, waste according to the e-waste guidelines.

Acknowledgements This research was supported by the Grant-in-Aid for Young Researchers (A)17H04722, the Japan Society for the Promotion of Science (JSPS), and by Science and Technology Research Partnership for Sustainable Development (SATREPS), Japan Science and Technology Agency (JST)/Japan International Cooperation Agency (JICA). 


\section{References}

1. State Council of China (2017) Implementation plan on banning entry of foreign garbage and reforming the administrative system of solid waste importation (plan) (in Chinese). No. 70, 2017. State Council of China, July 27, 2017. https://www.gov.cn/zheng ce/content/2017-07/27/content_5213738.htm. Accessed 12 Mar 2020

2. Brooks AL, Wang S, Jambeck JR (2018) The Chinese import ban and its impact on global plastic waste trade. Sci Adv. https://doi. org/10.1126/sciadv.aat0131

3. Bing X, Bloemhof-Ruwaard J, Chaabane A, van der Vorst J (2015) Global reverse supply chain redesign for household plastic waste under the emission trading scheme. J Clean Prod 10315:28-39

4. Wang C, Zhao L, Lim MK, Chen W-Q, Sutherland JW (2020) Structure of the global plastic waste trade network and the impact of China's import Ban. Resour Conserv Recycl. https://doi. org/10.1016/j.resconrec.2019.104591

5. World Economic Forum (2019) New circular vision for electronics: time for a global reboot. The Platform for Accelerating the Circular Economy (PACE)

6. Tong X, Wang T, Chen Y, Wang Y (2018) Towards an inclusive circular economy: quantifying the spatial flows of e-waste through the informal sector in China. Resour Conserv Recycl 135:163171. https://doi.org/10.1016/j.resconrec.2017.10.039

7. Yang H, Zhang S, Ye W, Qin Y, Meng Xu, Han L (2020) Emission reduction benefits and efficiency of e-waste recycling in China. Waste Manag 102(1):541-549. https://doi.org/10.1016/j.wasma n.2019.11.016

8. Shen Qu, Guo Y, Ma Z, Chen W-Q, Liu J, Liu G, Wang Y, Ming $\mathrm{Xu}$ (2019) Implications of China's foreign waste ban on the global circular economy. Resour Conserv Recycl 144:252-255. https:// doi.org/10.1016/j.resconrec.2019.01.004

9. Ministry of Industry (MOI) (2018) Ministry of Industry urges to not import waste electronic, used plastic and alloy scrap are absolutely ready, with the cabinet proposing to consider next week. Prohibit factories from using raw materials from abroad (in Thai). https://www.industry.go.th/industry/index.php/th/ about/2017-04-20-15-23-14/item/40259-2018-06-27-13-08-54. Accessed 12 Mar 2020

10. Bangkok Post (2018) E-waste plant fight hits home. https://www. bangkokpost.com/thailand/special-reports/1482241/e-waste-plant -fight-hits-home. Accessed 12 Mar 2020

11. Pollution Control Department, and Ministry of Natural Resource and Environment (2019) Plastic waste management roadmap 2018 (in Thai) https://www.pcd.go.th/Info_serv/File/Plastic\%2520R oadmap.pdf. Accessed 12 Mar 2020

12. Sasaki S (2018) Issues with THAI WEEE (Waste Electrical and Electronic Equipment) recycling bill: comparison with other Asian countries. In: The Proceeding of PIM 8th national and 1st international conference on challenges and opportunities of ASEAN: innovative, integrative and inclusive development, pp L1-13

13. Secretariat of the Basel Convention (2019a) Technical guidelines on transboundary movements of electrical and electronic waste and used electrical and electronic equipment, in particular regarding the distinction between waste and non-waste under the Basel Convention (BC-14/5). http://www.basel.int/Portals/4/download. aspx?d=UNEP-CHW.14-7-Add.6-Rev.1.English.pdf. Accessed 12 Mar 2020

14. Secretariat of the Basel Convention (2019b) Further actions to address plastic waste under the Basel Convention (BC-14/13). http://www.basel.int/Portals/4/download.aspx?d=UNEP-CHWCOP.14-BC-14-13.English.pdf. Accessed 12 Mar 2020

Publisher's Note Springer Nature remains neutral with regard to jurisdictional claims in published maps and institutional affiliations. 